\title{
A FUZZY APPROACH TO PREDICT THE THERMAL PERFORMANCE OF SPIRAL SOLAR THERMAL COLLECTOR
}

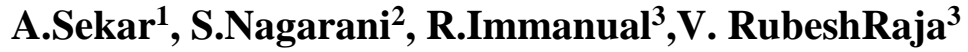 \\ ${ }^{1}$ Professor,Sri Ramakrishna Engineering College,Coimbatore \\ ${ }^{2}$ Professor,Sri Ramakrishna Institute of Technology,Coimbatore \\ ${ }^{3}$ AssistantProfessor,Sri Ramakrishna Institute of Technology,Coimbatore
}

Article History:Received:11 november 2020; Accepted: 27 December 2020; Published online: 05 April 2021 \begin{abstract}
In the recent scenario, the solar energy play a vital role for domestic usages since it is being one of the renewable forms of energy. The spiral solar thermal collector is used to harvest the solar energy. In the present work, the spiral solar thermal collector with specified dimensions was fabricated and the readings were taken. A Rule Based Mamdani Type Fuzzy (RBMTF) model was developed to predict the output temperature of the spiral solar thermal collector, using the mass flow rate of water, time as input parameters and outlet temperature as an output parameter with an aid of MATLAB fuzzy logic toolbox. The rate of flow is varied between 0.014 and 0.0755 for the time range of 600 minutes to 960 minutes. Six phonological variables were considered for each combination and the $\mathrm{R}^{2}$ value for the testing data were about $96.9 \%$. The predicted results were found to be in concurrence with the experimental results which confirm reliability of the proposed RBMTF model.
\end{abstract}

Keywords: RBMTF,spiral solar thermal collector,Flowrate,Outlet water temperature

\section{Introduction}

Increase in electricity consumption is one of the major challenges faced by the researchers in the development of a new system and in the up gradation of an existing systems. The electrical energy is obtained from various sources wherein the solar radiation is one among them. There are various instruments available to harvest solar power. A solar thermal collector is an opt solution to harvest solar power. Various studies are being carried out in the performance improvement of solar collector. One of the way to get improved performanceof solar collector is to change the shape of the collector. In the present work a spiral solar collector is chosen and a novel method using fuzzy logic is utilised to predict the output temperature of solar collector,since this tool has turned into one of the most favourable choice to deal with the prediction analysis of system performance.

Fuzzy logic is an artificial intelligence tool that involves phonological variables and experimental associations to approximate to match with the human reasoning and intuition.Fuzzy is well known for its ability to manipulate in solving complex problems with several conditions. It is a suitable tool for combining reckonable factors with qualitative interactive concepts. Fuzzy logic is a superset that works between completely false and true values. The controlling stages of any fuzzy systems involvesfuzzification, decision making and defuzzification.

A.F. Kothdiwalaet.al(2000), have developed a concentric parabola shaped solar thermal collector. The performance of the solar thermal collector was determined by changing the position and also by changing the reflector angles ${ }^{[1]}$. M. A. Al-Nimret.alhave studied the transient behaviour of the solar collector under the influence of incident radiation and inlet fluid ${ }^{[2]}$. X. A. Wanget.alhaveformulated a mathematical model to estimate the fluid mean temperature. The step input procedure was taken in which the various points in heating and cooling were noted, and were utilised to estimate the performance of the collector ${ }^{[3]}$. AfifHasanet.al(2001), have investigated the performance of the solar collector with varying collector cross sections. For a commercial shop, in a cost efficient basis the optimised area is found tobe $36 \mathrm{~m}^{2}$ for that particular application ${ }^{[4]}$. Concentric collectors are made to improve the concentration of solar radiation in the collectors. Theoretical investigation is done by [5] for $\mathrm{v}$ trough collector for optimal design of collector and adding to that thermal performance is also evaluated. Heat pipe with flat plate solar collector is investigated experimentally by [6] where freezing and corrosion is a major problem in the above collector type and it is improved in thermal performance. Due to the presence of thermo diode the whole day performance is little higher and it is cost effective than the double loop collector. Absorber plate also plays a major role in solar collector performance and [7] uses clay tile surface which absorb the solar radiation and exchange it to the flowing water. The efficiency is less in the above design in comparison with the conventional collector but the temperature difference between inlet and outlet is $11 \%$ higher in clay tile surface. The reason for less efficiency is due to the loss occurred in the clay tile surface. So design of absorber plate must be done in a way such that there should be less loss of heat. Water is always made to run above the absorber plate and in [8] water is made to run below the absorber plate in a wire screen. The thermal efficiency is much better about $15 \%$ increase than the conventional collector since more portion of the 
absorber plate is made in contact with water and therefore it increases the heat removal factor of the collector. Optical study was done by [9] in parabolic solar trough collector, where optical properties of the incident radiation its reflection and refraction with total optical efficiency was simulated. In order to monitor the daily performance of the solar collector, neural models have been used in [10] which is more accurate and the difference between evaluated model value and the actual value is found to be less than $0.5 \%$. Slope angle of the solar collector also made contribution in the performance, so it was investigated by [11] to find the optimum slope angle. Optimum slope is also calculated for monthly, yearly and seasonal period also for their local region. The optimum slope angle tends to be varies for different time throughout the year. An investigation and MATLAB simulation was done by [12] in solar parabolic collector in order to find out the influencing parameter of the collector. From the simulation results, solar collector is designed and is experimentally studied. Optimum value of some influencing parameters is studied using MINITAB. Carbon dioxide with supercritical condition is used as a heater transfer fluid flat plate solar collector by [13]. Results had been obtained for energy, exergy and second law efficiency and found out that the performance of the solar collector using super critical CO_2 is increased about 18\% than that of water. Evacuated tube collector is analyzed by [14] and the optimum parameters are identified, where the performance can fulfill $80 \%$ of air conditioning requirement. Thermal performance of a solar collector in a dryer is analyzed in [15] with two different cases, with or without collector. Improvement of about $16 \%$ had been outcomed with the use of a collector in the solar dryer. Radiation and thermal losses have been reduced by some modification in their design of the dryer.

Tarik A. Rashidand Havalet.al (2012),have performed modelling and planning astudentmanagement system based on gross point average in the registration department in the third level educational schemevia fuzzy concepts and the accuracy of results were appreciable ${ }^{[16]}$.Shakhawat, Tahir, and Neil (2006) have utilised fuzzy technique to calculate the human health hazards by radioactive materials present in formed water. The difficulty level was found to be high because of wide range of variables in the occurrence of cancer ${ }^{[17]}$.Keshwani, Jones, Meyer, and Brand (2008) applied a rule based Mamdani fuzzy logic for a skin model. They have concluded that the three input model has predicted superior than the two input model and also the former one showed less entropy than the later one ${ }^{[18]}$. T. Takagiet.al (1985) found that the fuzzy models have superior qualities than the numerical models since the interpretation was nearer to human thinking and also its ease of viability to work with nonlinearsystems ${ }^{[19]}$.

\section{Mamdani-type fuzzy rule modelling}

Zadeh has acquaint with fuzzy logic to build a numerical framework for the data that were presented vaguely, which was a common form of interval analysis with high and low values. In set theory the variable is considered to be a part of a set. The rank of the variable is assumed to be one if it lies inside set else it is taken as zero. Fuzzy is a non-conventional set theory wherein the elements have the certain degree of membership function. The output values of fuzzy set gives the correlation between the indeterminate data and the membership function whose value ranges from 0 to 1.The fuzzy implications illuminates a multifaceted fuzzy system. The above stated implications along with the experimental data can be developedas a mamdani model. The system planning can be done by mamdanimodels which uses more number of rules.

The input marix $(\mathrm{X})$ and the output vector $(\mathrm{g})$ of a fuzzy system are defined as follows

$\mathrm{X}=\left[\mathrm{x}_{1}, \mathrm{X}_{2}, \ldots \ldots, \mathrm{x}_{\mathrm{n}}\right]^{\mathrm{T}}$

$\mathrm{g}=\left[\mathrm{g}_{1}, \mathrm{~g}_{2}, \ldots \ldots ., \mathrm{g}_{\mathrm{n}}\right]$

The propositions of thefuzzy mamdani system includes both the antecedent and consequent. A common form of if-then rule of fuzzy is given by,

$R_{i}$ : if $x$ is $A_{i}$ then $y$ is $B_{i}, I=1,2, \ldots \ldots, k$.

In the above expression the rule number is expressed by $R_{i}$, the sets are represented by $A_{i} \& B_{i}$, and both the antecedent and consequent variables are represented by $\mathrm{x}, \mathrm{y}$.

The triangular membership function is given by ,

$$
\mu_{a}(x)=\left\{\begin{array}{c}
\frac{x-a}{b-a}, \quad a \leq x \leq b \\
\frac{x-c}{b-c}, b \leq x \leq c \\
0 ; \text { Otherwise }
\end{array}\right.
$$

The upper and lower values are a and c, the most likely value can be taken as $b$.

The process of obtaining unique value by converting the fuzzy outputs is termed as defuzzification, done by any one of the commonly available approaches includes COG, Weighted-Average approach. The defuzzified value for a set is given by,

$$
z^{*}=\frac{\int_{a}^{b} Z C(z) d z}{\int_{a}^{b} C(z) d z}
$$


Where $\mathrm{C}$ - fuzzy set in a problem

$\mathrm{a}, \mathrm{b}$ - interval containing support of $\mathrm{C}$.

\section{EXPERIMENTAL SETUP}

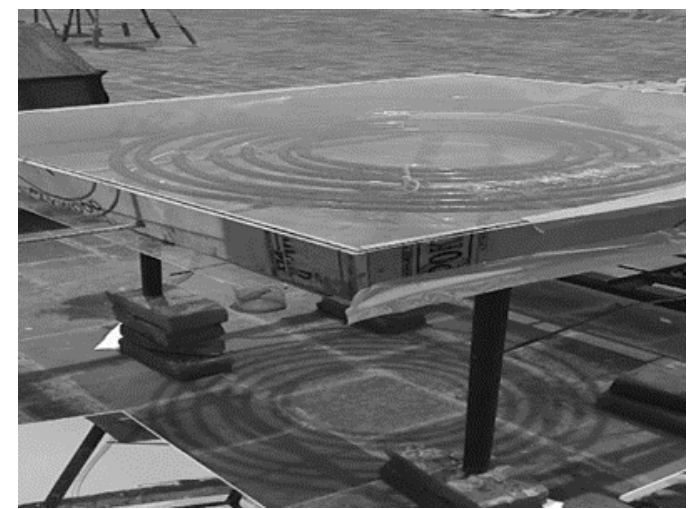

Fig. 1.View of spiral solar thermal collector

The Fig 1.Shows the fabricated model of the present experimental setup. The wooden chamber with 7.5 turns spiral coil was taken as the test model. This structure was placed on a mild steel rod. A natural water flow is obtained from water tank by giving an elevation. The outer and inner radius of copper coils were taken as 8 $\mathrm{mm}$ and $7.5 \mathrm{~mm}$. a glass cover of $1 \mathrm{~m}^{2}$ area was used to cover both sides of the wooden structure. The bottom side of the collector was covered by two plates of $0.5 \mathrm{~m}^{2}$ area to avoid the reflected rays from the ground.

\section{Experimental results}

The experimentations were being carried out at different time interval and with water flow rates. Thermometer and stopwatchwere used to measure both the inlet and outlet temperature and also the water flow rate.

Table 1 Experimental readings of solar spiral thermal collector|
\begin{tabular}{|l|c|c|c|}
\hline $\begin{array}{c}\text { LOCAL } \\
\text { SOLAR } \\
\text { TIME }\end{array}$ & $\begin{array}{c}\text { Mass flow } \\
\text { rate } \\
\mathrm{Kg} / \mathrm{sec}\end{array}$ & $\begin{array}{c}\text { Tin(K) } \\
\text { experimental }\end{array}$ & $\begin{array}{c}\text { Tout(K) } \\
\text { experimental }\end{array}$ \\
\hline $11 \mathrm{AM}$ & 0.055 & 310 & 314 \\
\hline $11 \mathrm{AM}$ & 0.036 & 310 & 316 \\
\hline $11 \mathrm{AM}$ & 0.014 & 310 & 318 \\
\hline $12 \mathrm{PM}$ & 0.055 & 310 & 314 \\
\hline $12 \mathrm{PM}$ & 0.036 & 310 & 316 \\
\hline $12 \mathrm{PM}$ & 0.014 & 310 & 318 \\
\hline 1 PM & 0.055 & 310 & 313 \\
\hline $1 \mathrm{PM}$ & 0.036 & 310 & 314 \\
\hline $1 \mathrm{PM}$ & 0.014 & 310 & 317 \\
\hline $2 \mathrm{PM}$ & 0.055 & 310 & 312 \\
\hline $2 \mathrm{PM}$ & 0.036 & 310 & 314 \\
\hline $2 \mathrm{PM}$ & 0.014 & 310 & 317 \\
\hline $3 \mathrm{PM}$ & 0.055 & 310 & 312 \\
\hline $3 \mathrm{PM}$ & 0.036 & 310 & 313 \\
\hline $3 \mathrm{PM}$ & 0.014 & 310 & 317 \\
\hline
\end{tabular}

The Table 1 shows the results of experiments that were carried out at different time intervals.Various outlet temperatures were obtained by varying the mass flow rate of the water that passes through the spiral tube. The velocity of water was measured from volume flow rate of water.

\section{Developed fuzzy expert system for thermal performance of Solar spiral Thermal Collector in} Tirunelveli of India

In this study, MATLAB fuzzy logic toolbox was used forRule Based MamdaniTF. To develop a RBMTF for thermal performance of Solar spiral Thermal Collector in Tirunelveli of India,two parameters, namely Time of the day andMassflowrate are considered as inputs, andOutlet water temperature as the output.

The Time of the day values used in the RBMTF modelling were taken fromthe Previous referred journals, and their values are $11 \mathrm{Am}(660 \mathrm{mins}), 12 \mathrm{Am}(720 \mathrm{mins}), 1 \mathrm{Pm}(780 \mathrm{mins}), 02 \mathrm{Pm}(840 \mathrm{mins})$, and 03Pm(900mins).. The mass flow ratevalues consists of $0.055 \mathrm{~kg} / \mathrm{sec}, 0.036 \mathrm{Kg} / \mathrm{sec}$, and $0.014 \mathrm{~kg} / \mathrm{sec}$. 


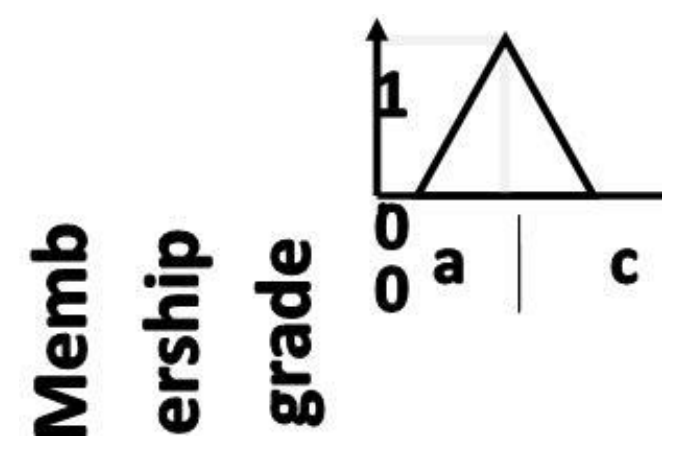

Fig. 2. Triangular Membership Function

The shape of the membership function distributions is assumedto be triangular (Fig. 2). The membership functions were developed to estimate the thermal performance of Solar spiral Thermal Collector, representing Very Low(L1), Medium Low(L2),Low (L3), Medium (L4), High (L5), and Very High (L6) phonological classes (Table 2).

Table 2Fuzzy sets of input and output variables.

\begin{tabular}{|c|c|c|c|c|c|c|}
\hline $\begin{array}{l}\text { Membership } \\
\text { name }\end{array}$ & $\begin{array}{ll}\text { Very } & \text { Low } \\
\text { (L1) } & \end{array}$ & $\begin{array}{l}\text { Medium } \\
\text { Low(L2) }\end{array}$ & Low (L3) & $\begin{array}{l}\text { Medium } \\
\text { (L4) }\end{array}$ & High (L5) & $\begin{array}{l}\text { VeryHigh } \\
\text { (L6) }\end{array}$ \\
\hline \multirow[t]{3}{*}{ Time } & L1 & - & L2 & L3 & L4 & L5 \\
\hline & $\mathrm{T} 1$ & - & $\mathrm{T} 2$ & $\mathrm{~T} 3$ & $\mathrm{~T} 4$ & T5 \\
\hline & $600-720$ & - & $660-780$ & $720-840$ & $780-900$ & $840-960$ \\
\hline \multirow{2}{*}{$\begin{array}{c}\text { Mass Flow } \\
\text { Rate }\end{array}$} & M1 & - & - & M2 & - & M3 \\
\hline & $\begin{array}{l}0.014- \\
0.0345\end{array}$ & - & - & $\begin{array}{c}0.014- \\
0.055\end{array}$ & - & $\begin{array}{l}0.0345- \\
.0755\end{array}$ \\
\hline \multirow{2}{*}{$\begin{array}{l}\text { Outlet Water } \\
\text { Temperature }\end{array}$} & OWT1 & OWT2 & OWT3 & OWT4 & OWT5 & OWT6 \\
\hline & $310.8-313.2$ & $312-314.4$ & $313.2-315.6$ & $\begin{array}{c}314.4- \\
316.8\end{array}$ & $315.6-318$ & $316.8-319.2$ \\
\hline
\end{tabular}

The fuzzy triangular membership functions for two input variables, time and mass flow rate are shown in Fig. 3(a) and (b), respectively.

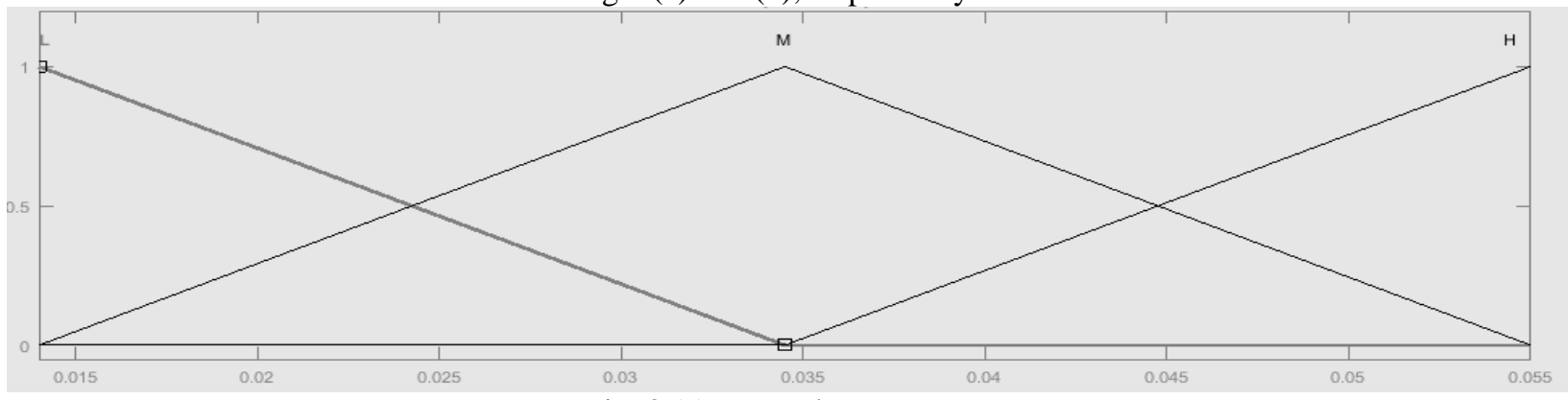

Fig. 3.(a) Mass Flow Rate

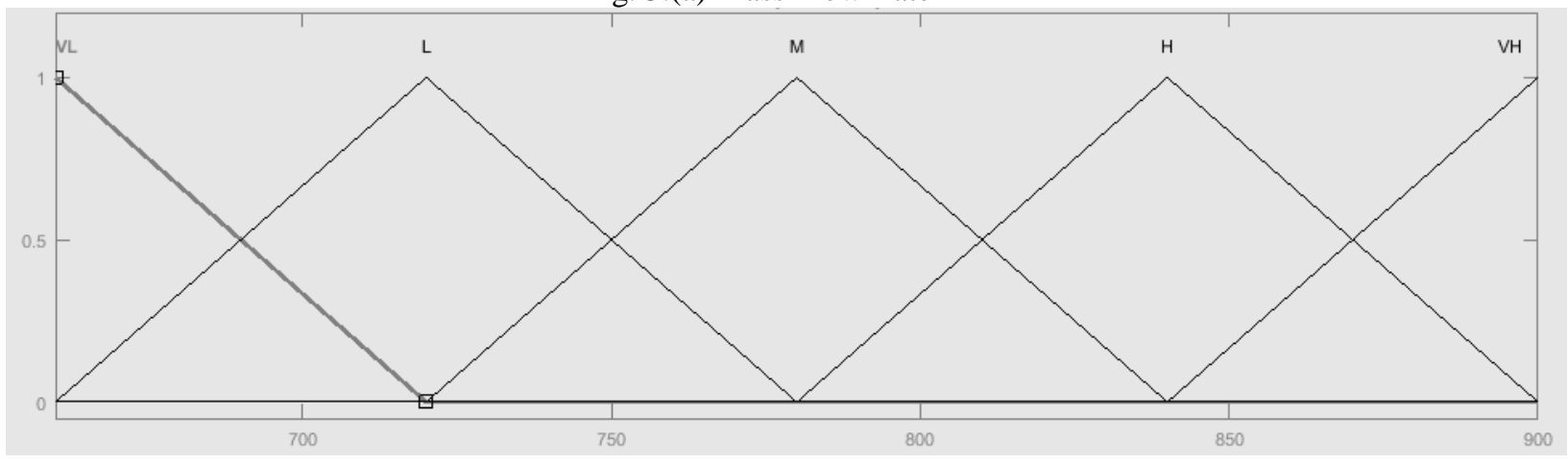


Fig. 3.(b)Time of the day

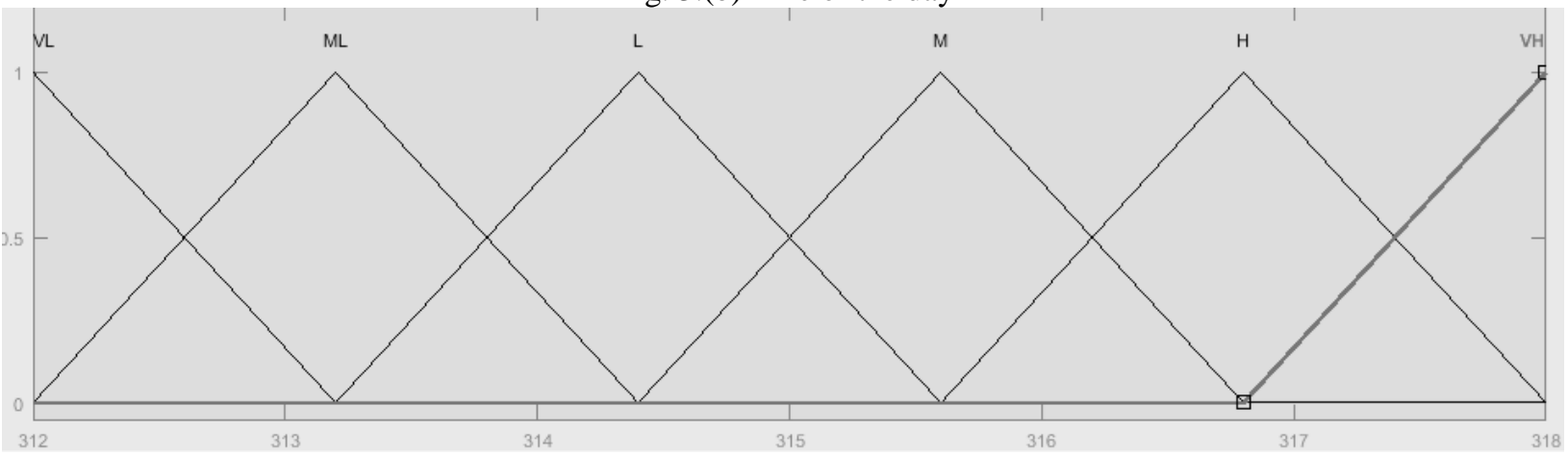

Fig. 4 Outlet water Temperature

Fig. 4.Shows the triangular membership function for the outlet water temperature.

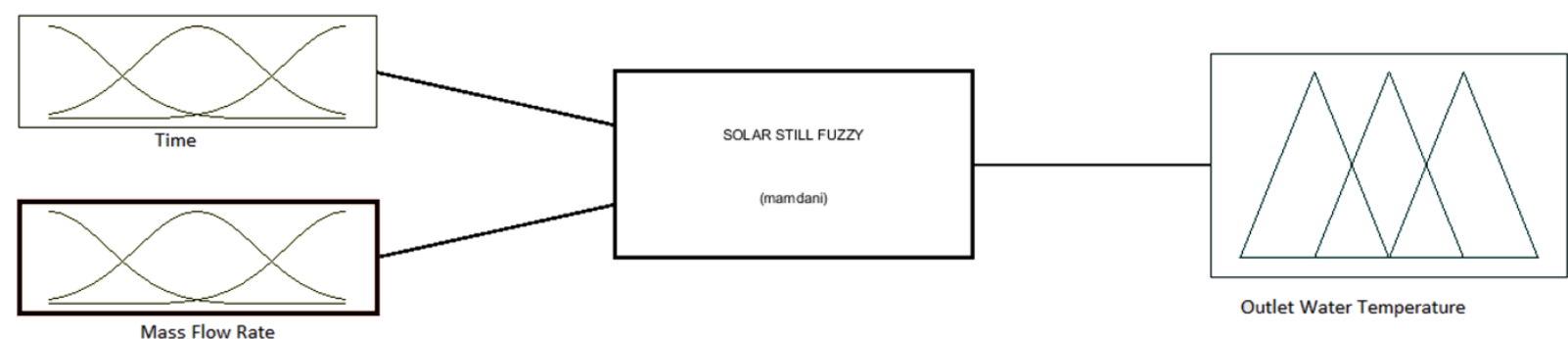

Fig. 5. General layout of fuzzy modelling structure for a spiral solar thermal collector

Fig .5.Shows the general layout of the dual- input and single -output RBMTF model for the present work. The two parameters namely, mass flow rate and time were taken as inputs and the outlet temperature was taken as an output for the modelling of RBMTFin MATLABfuzzy logic toolbox.

4. Results and discussion

Comparison between actual and RBMTF models

Table 3 .Actual and RBMTF data (rule,prediction)

\begin{tabular}{|c|c|c|c|c|c|c|}
\hline S.NO & $\begin{array}{l}\text { TIME } \\
\text { IN } \\
\text { MINS }\end{array}$ & $\begin{array}{l}\text { TIME } \\
\text { IN HRS }\end{array}$ & $\begin{array}{l}\text { MASS } \\
\text { FLOW } \\
\text { RATE }\end{array}$ & $\begin{array}{l}\text { ACTAL WATER } \\
\text { OUTLET } \\
\text { TEMPERATURE }\end{array}$ & Rule Number & $\begin{array}{l}\text { FUZZY PREDICTED } \\
\text { OUTLET WATER } \\
\text { TEMPERATURES }\end{array}$ \\
\hline 1 & 660 & 11 & 0.055 & 314 & I & 314 \\
\hline 2 & 660 & 11 & 0.036 & 316 & II & 315 \\
\hline 3 & 660 & 11 & 0.014 & 318 & III & 318 \\
\hline 4 & 720 & 12 & 0.055 & 314 & IV & 314 \\
\hline 5 & 720 & 12 & 0.036 & 316 & V & 317 \\
\hline 6 & 720 & 12 & 0.014 & 318 & VI & 318 \\
\hline 7 & 780 & 1 & 0.055 & 313 & VII & 313 \\
\hline 8 & 780 & 1 & 0.036 & 314 & VIII & 314 \\
\hline 9 & 780 & 1 & 0.014 & 317 & IX & 317 \\
\hline
\end{tabular}




\begin{tabular}{|c|c|c|c|c|c|c|}
\hline 10 & 840 & 2 & 0.055 & 312 & $X$ & 312 \\
\hline 11 & 840 & 2 & 0.036 & 314 & XI & 314 \\
\hline 12 & 840 & 2 & 0.014 & 317 & XII & 317 \\
\hline 13 & 900 & 3 & 0.055 & 312 & XIII & 312 \\
\hline 14 & 900 & 3 & 0.036 & 313 & XIV & 313 \\
\hline 15 & 900 & 3 & 0.014 & 317 & XV & 317 \\
\hline
\end{tabular}

Table 3 shows the outlet water temperature obtained using real experiments and also by predictions fromRBMTF. From the table 3 it is clear that the predicted temperature values are in concurrence with the actual one. Hence, the mamdanirule based fuzzy systems can be effectively employed to predict the output temperature of the spiral solar thermal collector.

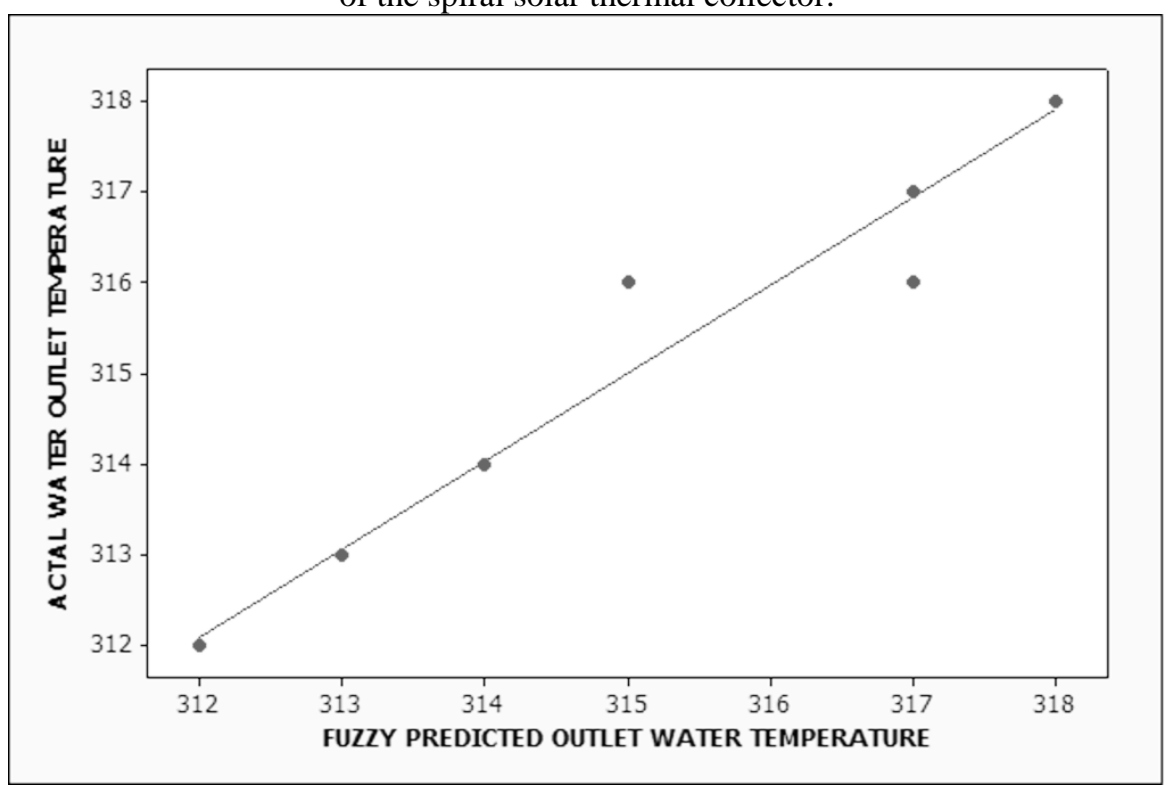

Fig .6. Comparison plot of actual data and RBMTF-predicted values of Outlet water temperature

Fig .6.Shows the comparison plot drawn between the outlet water temperature values obtained by actual experiments and RBMTF predictions. From the above figure it is clear that the RBMTF predictions are in line with the actual values.

Also from table 4 it is clear that there can be a strong correlation between the obtained values from actual experiment and from RBMTF models since the $\mathrm{R}^{2}$ is 0.967 .

Table 4The statistical error values for Outlet water temperature

\begin{tabular}{|l|l|l|}
\hline $\mathrm{R}^{2}$ & Max error (\%) & Average error (\%) \\
\hline $96.9 \%$ & 0.316456 & 0.042194093 \\
\hline
\end{tabular}

\section{Effect of flow rate and time on outlet temperature}




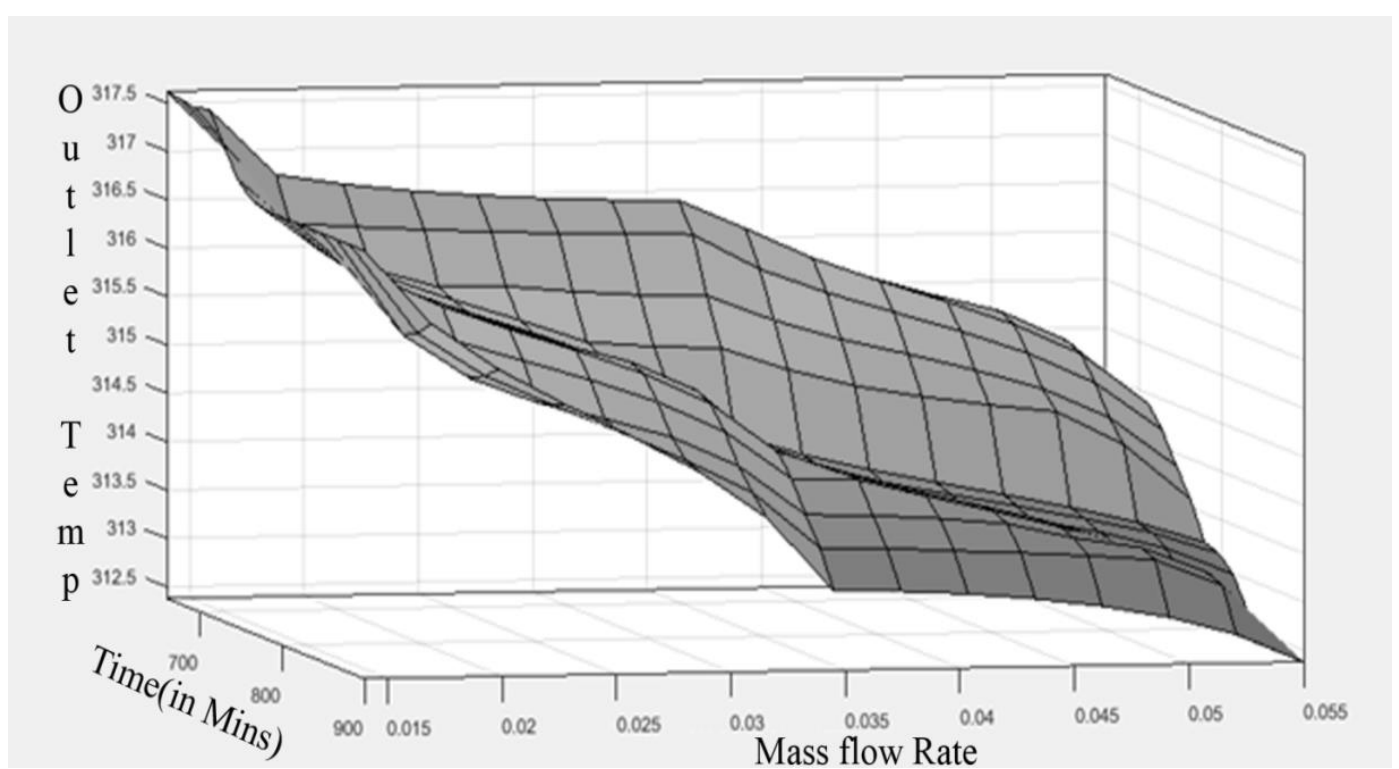

Fig .7. Output surface for outlet temperature of spiral thermal collector

Fig.7. shows the relationship between the outlet temperature (dependent variable) with the time and mass flow rate (independent variables). From the surface plot it is evident that the maximum output temperature is attainedat $0.015 \mathrm{Kg} / \mathrm{S}$ mass flow rate and at 720 Minutes.

\section{Conclusion}

The objective of the present work is to develop the RBMTFmodel to predict the thermal performance of the solar thermal collector. For this stated objective various research articles were reviewed and the spiral shaped thermal collector was chosen for further analysis. The spiral shaped thermal collector is fabricated and the readings at various time intervals were taken later which they were utilised to create a RBMTF model using MATLABfuzzy logic toolbox. The output temperature values were predicted for the developed RBMTF model using MATLABfuzzy logic toolbox and the $\mathrm{R}^{2}$ valuebetween the actual and predicted temperatures was found to be 0.969 which can be used to conclude that the predicted values of RBMTF model are in strong correlation with the actual values. Hence, the mamdani rule based fuzzy model can be employed to predict the thermal performance of spiral solar thermal collector. From the surface plot it is clear that the maximum outlet temperature was attained at $0.015 \mathrm{Kg} / \mathrm{S}$ water flow rate and at 720 Minutes. Thus the proposed system can be very much useful in analysing the thermal performance of the spiral solar thermalcollector. In future, this system can be clubbed with intelligent systems.

\section{References}

A.F. Kothdiwala, P.C. Eames and B. Norton, Convective heat transfer correlations for an enclosed horizontal compound parabolic cavity solar thermal collector, Int. J, of Solar Energy, 2000. Vol. 20, pp. 161-175.

M. A. Al-Nimr, Transient behaviour of a particulate solar collector, International Journal of Solar Energy, 13:3, 205-214, DOI: 10.1080/01425919208909785.

X. A. Wang, Y. F. Xu\& W. C. Lou (1986) Solar collector parameter identification by step input test procedure, International Journal of Solar Energy, 4:6, 327-334, DOI: 10.1080/01425918608909868.

AfifHasan (2001) Optimization of collector area in solar water heating systems, International Journal of Solar Energy, 21:1, 19-27, DOI: 10.1080/01425910008914361.

M. M. Sorour , A. A. M. Abdou\& R. A. Mahmoud (1991) Design of stationary finite length v trough solar collector, International Journal of Solar Energy, 10:1-2, 63-81, DOI: 10.1080/01425919108941452.

Lu Wei De \&GuoHui Fen (1985) Experimental Study on the Performance of a Gravity-assisted Heat Pipe Flat Plate Solar Collector, International Journal of Solar Energy, 3:1, 1-11, DOI: 10.1080/01425918408914378.

Ali A. BAdran\& Ahmad F. Badran* (1998) An integrated solar collector/roof system utilizing a water-trickle clay-tile collector, International Journal of Solar Energy, 19:4, 213-231, DOI 10.1080/01425919808914338.

ALI A. BADRAN\&YUSEF S. H. NAJJAR (1993) THE INVERTED TRICKLE FLAT PLATE SOLAR COLLECTOR, International Journal of Solar Energy, 14:1, 33-41, DOI: 10.1080/01425919308909794.I

Roberto Grena (2010) Optical simulation of a parabolic solar trough collector, International Journal of Sustainable Energy, 29:1, 19-36, DOI: 10.1080/14786450903302808.

Sylvain Lalot\&StéphaneLecoeuche (2003) Neural models of solar collectors for prediction of daily performance , International Journal of Sustainable Energy, 23:1-2, 39-49, DOI: 10.1080/01425910310001634442 
M. Abdolzadeh\& M. A. Mehrabian (2011) Obtaining maximum input heat gain on a solar collector under optimum slope angle, International Journal of Sustainable Energy, 30:6, 353-366, DOI: 10.1080/1478646X.2010.515743.

P. Venkataramaiah, P. Mohana Reddy \& P. Sairam (2014) Simulation and optimisation studies on a solar parabolic collector: an experimental investigation, International Journal of Sustainable Energy, 33:4, 869882, DOI: 10.1080/14786451.2013.778859.

JaharSarkar (2013) Performance of a flat-plate solar thermal collector using supercritical carbon dioxide as heat transfer fluid, International Journal of Sustainable Energy, 32:6, 531-543, DOI: 10.1080/14786451.2013.833205.

Adel A. Ghoneim (2016): Performance optimization of evacuated tube collector for solar cooling of a house in hot climate, International Journal of SustainableEnergy, DOI: 10.1080/14786451.2016.1256886.

Prashant Singh Chauhan\& Anil Kumar (2016): Thermal analysis of insulated north-wall greenhouse with solar collector under passive mode, International Journal of Sustainable Energy, DOI: 10.1080/14786451.2016.1261866.

Tarik A. Rashid,HavalAbdulkarim Ahmed (2012): Revised General Test/Gross Point Average System via Fuzzy Logic

Techniques,JOURNAL OF COMPUTER SCIENCE AND ENGINEERING, VOLUME 16, ISSUE 1, NOVEMBER 2012

Shakhawat, C., Tahir, H., \& Neil, B. (2006). Fuzzy rule-based modelling for human health risk from naturally occurring radioactive materials in produced water, Journal of Environmental Radioactivity, 89, 1-17.

Keshwani, D. R., Jones, D. D., Meyer, G. E. R., \& Brand, M. (2008). Rule-based Mamdani-type fuzzy modelling of skin permeability. Applied Soft Computing, 8,285-294.

T. Takagi, T. Sugeno, Fuzzy identification of system and its applications to modelling and control, IEEE Trans. Syst. Man Cybern. 15 (1985) 116e132. 